
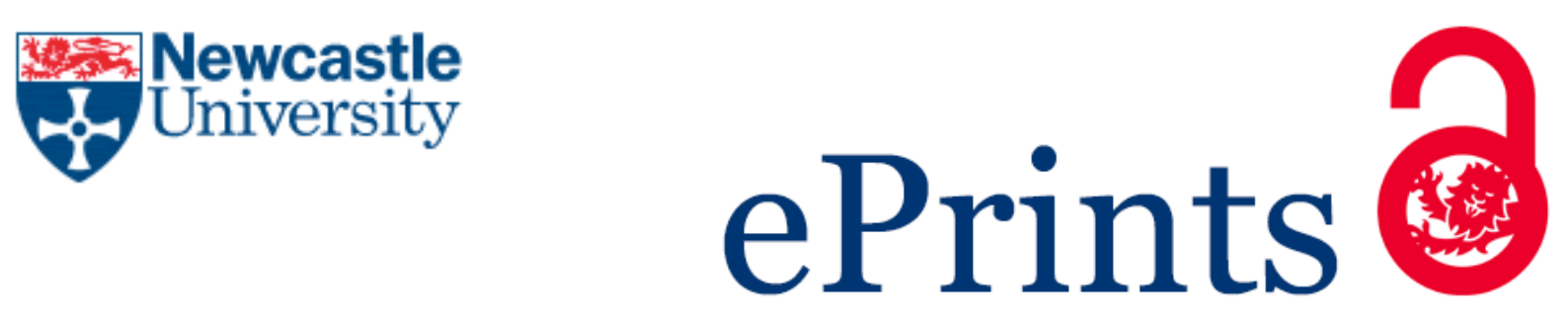

Kampouraki E, Kamali F.

Dietary implications for patients receiving long-term oral anticoagulation therapy for treatment and prevention of thromboembolic disease. Expert Review of Clinical Pharmacology 2017

DOI: https://doi.org/10.1080/17512433.2017.1345622

\title{
Copyright:
}

This is an Accepted Manuscript of an article published by Taylor \& Francis in Expert Review of Clinical Pharmacology on 21/06/2017, available online:

http://www.tandfonline.com/10.1080/17512433.2017.1345622

DOI link to article:

https://doi.org/10.1080/17512433.2017.1345622

Date deposited:

$20 / 07 / 2017$

Embargo release date:

21 June 2018

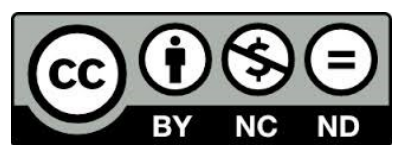

This work is licensed under a

Creative Commons Attribution-NonCommercial-NoDerivatives 4.0 International licence 


\section{Dietary implications for patients receiving long-term oral anticoagulation therapy for treatment and prevention of thromboembolic disease}

Emmanouela Kampouraki and Farhad Kamali

Institute of Cellular Medicine, Newcastle University, Newcastle upon Tyne, NE2 4HH, United Kingdom

Correspondence: Professor Farhad Kamali, Institute of Cellular Medicine, $4^{\text {th }}$ Floor William Leech Building, Newcastle University, Newcastle upon Tyne, UK; E-mail: farhad.kamali@ncl.ac.uk; Tel: +44 191 2088043; Fax: +44 1912085827 


\section{Abstract}

Introduction: The effectiveness of oral anticoagulation therapy with warfarin (a vitamin $\mathrm{K}$ antagonist) in the treatment of thromboembolic disease, including stroke prophylaxis in patients with atrial fibrillation is well recognised. However, warfarin has a narrow therapeutic window and an unpredictable anticoagulation response, which make it difficult to achieve and maintain optimal anticoagulation. Various dietary factors, including sudden changes in eating patterns, can significantly alter anticoagulation control, thereby potentially exposing patients to the risk of bleeding or thromboembolic complications. Dietary vitamin $\mathrm{K}$ intake is a particularly important factor, given the mechanism of action of warfarin.

Areas covered: In this review, we cover the sources of vitamin $\mathrm{K}$ and their potential effect of dietary vitamin $\mathrm{K}$ on anticoagulation response to warfarin. We also discuss the results of studies on the effect of vitamin $\mathrm{K}$ supplementation on anticoagulation stability.

Expert Opinion/Commentary: A stable dietary vitamin $\mathrm{K}$, promoted by daily oral vitamin $\mathrm{K}$ supplementation, can improve anticoagulation stability in patients on warfarin therapy. There is experimental evidence in animals that dietary vitamin $\mathrm{K}$ affects anticoagulation response to the direct thrombin inhibitor, ximelagatran. Whether dietary vitamin $\mathrm{K}$ affects anticoagulation response to direct oral anticoagulants (DOACs) in man remains to be investigated.

Word count: 196

Keywords: lifestyle, nutrition, thromboembolic disease, vitamin $\mathrm{K}$ antagonists, anticoagulation, warfarin, direct oral anticoagulants 


\section{Introduction}

Thromboembolic disease, including stroke in patients with atrial fibrillation (AF), accounts for significant morbidity, mortality and economic burden in the developed world. AF is a common cardiac arrhythmia that affects over 33.5 million people globally (1) and is the strongest known risk factor (5-fold) for stroke (2) with the association between atrial fibrillation and stroke of cardioembolic origin being widely recognised. (3) The percentage of atrial fibrillation-attributed strokes increases with age, with a 16-fold increase between patients aged 50-59 and $80-89$ years $(1.5 \% \vee 23.5 \%$ respectively). (4) The total annual cost for stroke treatment in the USA between 2011 and 2012 was estimated to be $\$ 33$ billion (5). Venous thromboembolism, including deep vein thrombosis and pulmonary embolism affect 133 per 100.000 of the population in the USA. Further, venous thromboembolism recurs in about $30 \%$ of individuals within the next 10 years. (6)

Coumarins, such as warfarin, phenprocoumon and acenocoumarol, have been the mainstay of oral anticoagulation therapy for the treatment of thromboembolic disease for more than 65 years. Randomised controlled studies have demonstrated that anticoagulation therapy with warfarin significantly reduces the overall risk of stroke, its severity and the associated risk of death in patients with AF. $(7,8)$ Consequently, treatment guidelines advocate the use of warfarin prophylaxis in patients with AF at moderate-to-high risk of stroke. (9)

Vitamin $\mathrm{K}$ (as vitamin $\mathrm{K}$ hydroquinone) is an essential cofactor needed for the $\gamma$ carboxylation of glutamic acid residues located at the amino-terminals of the vitamin Kdependent clotting proteins II, VII, IX and X, leading to their activation. (10) Coumarins cause anticoagulation by interfering with the cyclic interconversion of vitamin $\mathrm{K}$ hydroquinone (hence also referred to as 'vitamin $\mathrm{K}$ antagonists') thus reducing the activation of vitamin K-dependent clotting proteins.

Achieving effective and safe anticoagulation with warfarin, however, is a major challenge in routine medical care because many factors can influence the pharmacodynamic 
effect of this drug. Whilst several factors including concurrent disease, drugs and patient compliance have been identified as affecting warfarin requirements in a predictable way, the observed intra-individual variability in anticoagulation response to warfarin cannot be fully explained at the present. There is evidence that dietary factors can make a significant contribution to unstable control of anticoagulation. In this article, we will discuss the potential impact of dietary factors on patients receiving long-term oral anticoagulation therapy with warfarin for the treatment and prevention of thromboembolic disease and the positive influence of daily vitamin $\mathrm{K}$ supplementation on anticoagulation control. We will also point to the potential impact of dietary vitamin $\mathrm{K}$ on the pharmacological activity of the more recently developed direct oral anticoagulants (DOACs).

\section{Dietary factors and anticoagulation control}

\section{Dietary vitamin K intake}

Vitamin $\mathrm{K}$ is a fat-soluble vitamin that is largely derived from the diet, predominantly as phylloquinone (vitamin $\mathrm{K}_{1}$ ), present notably in green leafy vegetables and vegetable oils (Table 1). Given that the activation of the main clotting factors (II, VII, IX and X) is dependent on vitamin $\mathrm{K}$ availability, anticoagulation control during warfarin therapy is highly sensitive to fluctuating levels of vitamin $\mathrm{K}$ in the diet. (11-13)

As there is no detailed assessment of usual population intake in relation to measurable health outcomes, daily Recommended Dietary Requirement (RDA) for vitamin K cannot be set. The current "dietary reference value" of $1 \mu \mathrm{g} / \mathrm{kg}(\sim 65-80 \mu \mathrm{g}$ of phylloquinone/day in an average sized individual) is based on coagulation factor function; substantially higher recommended daily doses have been suggested because of findings that the requirement for vitamin $\mathrm{K}$ is greater for the extra-hepatic vitamin $\mathrm{K}$-dependent proteins, including those found in bone (e.g. osteocalcin). (14) In 2001, the adequate intake (Al) level for vitamin $\mathrm{K}$ based on 
consumption levels in healthy individuals was established (Table 2). Neither pregnancy nor lactation necessitate additional vitamin K uptake in women. (15) A previous study of dietary intake of vitamin $\mathrm{K}$ in a national sample of British elderly people demonstrated that $59 \%$ had an intake below $1 \mu \mathrm{g} / \mathrm{kg} /$ day. (16)

Of all the fat-soluble vitamins, vitamin $\mathrm{K}$ has the highest individual daily variation in both dietary intake and corresponding plasma concentrations. This is because, dark green vegetables which are the main source of vitamin $\mathrm{K}$, are not consistently consumed on a daily basis. For example, in a study of post-menopausal women in New England, USA, intake ranged from 3-2761 $\mu$ g of phylloquinone/day. (17)

Sudden changes in dietary vitamin $\mathrm{K}$ intake resulting in poor anticoagulation control may put patients at increased risk of potential life-threatening bleeding and thromboembolic complications. Indeed, prosthetic valve thrombosis (18) and myocardial infarction (19) have been reported in patients who increased their vitamin $\mathrm{K}$ intake during anticoagulation therapy, and in the case report by Walker (19) this was linked to the patient embarking on a vegetablerich, weight-reduction diet. Conversely, diffuse bruising (presumably due to enhanced anticoagulation) in one case report was linked to the patient stopping his consumption of large amounts of porcine liver, thereby reducing his vitamin $\mathrm{K}$ intake (18). Thus, it has been suggested that patients maintain a consistent dietary vitamin $\mathrm{K}$ intake during anticoagulation therapy, generally no more than 250 to $500 \mu \mathrm{g} /$ day (20).

An earlier crossover study in anticoagulated patients demonstrated an inverse relationship between vitamin $\mathrm{K}$ intake and anticoagulation response, as measured by the International Normalised Ratio (INR). (12) Another study in patients on chronic therapy with warfarin and with stable control of anticoagulation demonstrated that for every $100 \mu \mathrm{g}$ increase in vitamin $\mathrm{K}$ intake over the previous 4 days, INR value fell by 0.2 units (21), further clarifying the extent of the inter-relationship between dietary vitamin $\mathrm{K}$ and the INR. Consistent with these observations, Lubetsky et al. found that, INR values decreased in $32 \%(16 / 50)$ of 
anticoagulated patients following a vitamin $\mathrm{K}$ intake of $\geq 250 \mu \mathrm{g} / \mathrm{day}$. The patients had significantly lower median INR values $(1.9$ and 3.0 , respectively; $p<0.001)$ and required a higher maintenance steady state warfarin dose (5.7 and $3.5 \mathrm{mg} /$ day, respectively; $p<0.001)$, compared to those receiving $<250 \mu \mathrm{g} /$ day of vitamin $\mathrm{K}$. (11)

In order to reduce intra-patient variability in anticoagulation response, patients should maintain an adequate and consistent intake of dietary vitamin $\mathrm{K}$ that at least meets the current dietary reference value of $65-80 \mu \mathrm{g} /$ day. Self-monitoring of vitamin $\mathrm{K}$ intake aids, such as the 'K-Card', which was designed as a checklist of common foods and beverages providing $\geq 5 \mu \mathrm{g}$ vitamin $\mathrm{K}$ per serving (Table 3), may be helpful in this regard. (22)

\section{Dietary supplements}

\subsection{Enteral feeds}

Enteral feeds may be an unsuspected source of additional dietary vitamin $\mathrm{K}$ in patients receiving warfarin. Although a decrease in the vitamin $\mathrm{K}$ content of enteral feedings has been observed over the years (23), some feeds may contain for example up to $20 \mu \mathrm{g}$ vitamin $\mathrm{K}$ per $8 \mathrm{fl} \mathrm{oz}(237 \mathrm{ml})$ serving (Table 4). This may explain why certain enteral feeds have been reported to lower the anticoagulant effect of warfarin. (24-26) Thus, it is important to consider the significant impact of enteral nutrition on anticoagulation response in patients on warfarin therapy.

Vitamin $\mathrm{K}$ also plays a key role in anticoagulation control in children. The main sources of phylloquinone in neonates, especially preterm infants, are the prophylactic dose of phylloquinone given at birth, along with the vitamin $\mathrm{K}$ intake derived from either parenteral and/or enteral feeding. Breast-fed infants, due to low quantity of vitamin $\mathrm{K}$ in human milk, are more sensitive to the anticoagulant effect of warfarin compared to formula-fed infants. Infant 
formula preparations with high vitamin $\mathrm{K}$ content frequently administered to pre-term neonates, lead to higher warfarin dose requirements. $(27,28)$

\subsection{Other supplements}

Vitamin $\mathrm{K}$ is a constituent of many multivitamin preparations. The anticoagulant effect of vitamin $\mathrm{K}$ antagonists is lessened even by multivitamin formulations containing small amounts of vitamin K. In relation to this, Kurnik et al. reported three cases of patients treated with warfarin who had presented with sub-therapeutic INR after taking multivitamin supplements containing vitamin $\mathrm{K}$, which necessitated an increase in warfarin dose with one patient experiencing major thrombosis. (29) One of the patients, whose warfarin requirements had increased from 45 to $60 \mathrm{mg}$ per week, discontinued the multivitamin preparation without notifying her physician and subsequently experienced haematoma accompanied by an INR of 13.2. (29) Consequent to these observations, patients are best advised to avoid multivitamin preparations containing vitamin $\mathrm{K}$.

There is evidence that vitamin $\mathrm{E}$ interferes with vitamin $\mathrm{K}$ metabolism, as demonstrated by an increase in PIVKA-II (protein induced by vitamin $\mathrm{K}$ absence factor II) plasma concentrations. $(30,31)$ Both vitamin $\mathrm{K}$ and vitamin $\mathrm{E}$ are metabolised by CYP4F2 enzyme, which may explain the basis for their interaction. (32) However, in a randomised double-blind study, vitamin E at relatively high doses (800 or 1200 IU/day) was shown to have no effect on warfarin anticoagulation. (33)

Vitamin $C$ has been reported to interact with warfarin in vitro. $(34,35)$ The suggested mechanisms of this interaction include enzyme induction leading to enhanced warfarin metabolism, potentiation of vitamin $\mathrm{K}$ activity, influence in either the synthesis or the rate of catabolism of the vitamin K-dependent clotting factors, and capillary fragility. (36) A more recent study in rats in vivo demonstrated that the co-administration of vitamin $\mathrm{C}$ with warfarin leads to an increase in the activity of coagulation factors II, VII, IX and X and a decrease in PT and APTT. (37) Contrary to these findings however, it has been reported that vitamin $\mathrm{C}$ does 
not alter the anticoagulant effect of warfarin in either dogs or guinea pigs. $(36,38)$ In patients on chronic warfarin therapy, we found no association between dietary vitamin C levels (2.2$95.9 \mu \mathrm{M})$ and warfarin dose requirement. (39)

The provitamin coenzyme Q10 (ubidecarenone) is a dietary supplement taken for a range of cardiovascular disorders (40) and has been linked to decreased anticoagulation when taken with warfarin (41). Coenzyme Q10 is structurally related to vitamin $\mathrm{K}$ and thus may have procoagulant effects in anticoagulated patients. (42) There are four case reports of falls in INR values following the co-administration of coenzyme Q10 with warfarin and subsequent restoration of initial INR values after discontinuation of coenzyme Q10. (43-45) A study in patients receiving long-term anticoagulation therapy however found that concomitant coenzyme Q10 intake (100 mg/day) had no significant effect on warfarin dose requirements. (46) As, at the present, there are conflicting reports about the effect of coenzyme Q10 on anticoagulation response to warfarin, patients should be advised to, either avoid the concomitant use of coenzyme Q10, or for healthcare providers to perform additional INR tests when patients start or stop taking coenzyme Q10.

Fish oils contain eicosapentaenoic and docosahexaenoic acids, which may inhibit vitamin K-dependent coagulation factors. One case report described elevated INR values when the patient concerned had taken fish oil supplement with warfarin. (47) However, this contrasts with the findings of an earlier placebo-controlled, randomised, double-blinded study in 16 patients receiving chronic warfarin therapy, in whom fish oil supplementation (36 grams/day) was shown to have no significant effect on anticoagulation control. (48) In the absence of further information, patients are advised to discuss the possible interaction between fish oil supplements and warfarin with their healthcare provider.

Recently, Cambria-Kiely reported the case of a 70-year-old man with hypertriglyceridaemia who was stable on long-term warfarin (INR 2.3-2.5) before he started drinking soya milk. Shortly thereafter, his INR dropped below the therapeutic range (1.6); when 
he stopped taking soya milk, his INR returned to the therapeutic range. (49) Interestingly, while soybeans and soybean oil contain high amounts of vitamin K (see Table 1), soya milk contains only trace amounts of the vitamin. (49) Further confirmation of the existence of an interaction between warfarin and soya milk and the possible mechanism for such interaction is needed. In the absence of further information, patients on warfarin therapy should avoid introducing soya milk into their diet.

Supplements containing L-carnitine have been found to enhance the anticoagulant effect of the vitamin $\mathrm{K}$ antagonist, acenocoumarol. The mechanism for such interaction is unclear. Whether L-carnitine also interacts with warfarin or phenprocoumon is unknown at this stage. Therefore, patients on vitamin $\mathrm{K}$ antagonists are advised to discuss with their healthcare provider the possible risks before taking L-carnitine. $(50,51)$

\subsection{Plant materials}

Interactions between herbs and other plant material and warfarin are commonly reported, sometimes with serious consequences of major bleeding. (52) Theoretically, any herb or plant material that may contain compounds related to coumarin or salicylate can augment the anticoagulant effect of vitamin $\mathrm{K}$ antagonists, through inhibition of either blood clotting or platelet aggregation. (53)

Up until 2014, thirty eight different herbs had been reported in the literature with the potential to interact with warfarin. Evidence suggests that the likelihood of an interaction with warfarin is high (level I) for four of these herbs, probable (level II) for three, possible (level III) for ten and doubtful (level IV) for twenty one. (54)

Garlic, ginkgo, St. John's wort, cranberry, grapefruit, cannabis, chamomile and red clover have been identified as having major interaction with warfarin. (54) Few reports have linked the use of garlic and gingko biloba with bleeding; however, there is no evidence that they directly affect coagulation. Ginger has been shown to inhibit platelet aggregation. (53), 
which may potentiate the anticoagulant effect of warfarin. There have been case reports of an interaction between St John's wort (Hypericum perforatum) and vitamin $\mathrm{K}$ antagonists (warfarin, phenprocoumon), where the use of St John's wort resulted in the lowering of INR and unstable control of anticoagulation. (55) A single case of raised INR after concomitant use of Angelica sinensis (Dong quai) and warfarin has been reported. (56) Enhanced anticoagulation and bleeding events have been reported after patients on warfarin therapy took the traditional Chinese medicine, Salvia miltiorrhiza (danshen). $(53,57)$

There have been several reports of interaction between warfarin and cranberry juice (58-60). For instance, an elderly patient on warfarin who had a poor appetite following a chest infection consumed very little except cranberry juice and was admitted to hospital 6 weeks later with an INR of $>50$. He died of gastrointestinal and pericardial haemorrhage. (61) The advice of the UK Committee on Safety of Medicines is to limit the intake of cranberry juice in patients taking warfarin. (61) The mechanism of the interaction between warfarin and cranberry juice is at present unclear. However, it has been suggested that the flavonoids present in cranberry juice, which can inhibit CYP2C9 enzyme responsible for (S)- warfarin metabolism, can explain the interaction between cranberry juice and warfarin. (62) It is plausible that vitamin $\mathrm{C}$, also a constituent of cranberry juice, contributes to alteration in anticoagulation response to warfarin, possibly by a number of mechanisms, including alterations in warfarin metabolism, competition with vitamin $\mathrm{K}$ in binding to vitamin $\mathrm{K}$ epoxide reductase which is the target enzyme for warfarin, and the rate of loss or catabolism of the vitamin K-dependent clotting factors.

It may also be pertinent to avoid the consumption of grapefruit juice given reports of enhanced warfarin anticoagulation after consuming grapefruit juice. (63) Although an earlier controlled study failed to demonstrate an interaction between warfarin and grapefruit juice (64), other studies have reported that grapefruit juice enhances the anticoagulant effect of warfarin by inhibiting mainly CYP3A4 and CYP2C9 enzymes involved in warfarin metabolism. $(65,66)$ 
Green tea, which is often taken as a dietary supplement because of its reputed health benefits (including antioxidant and antibacterial properties), contains substantial amounts of vitamin $\mathrm{K}$ and therefore drinking large amounts may antagonise the anticoagulant effects of warfarin. (67) Indeed, one report describes a warfarin-treated patient who experienced a marked decrease in INR after daily consumption of large amounts of green tea, with a subsequent INR increase when the beverage was discontinued (without a change in warfarin dosage). (68) In the absence of further information, patients receiving anticoagulation therapy are advised to discuss the consumption of green tea and its possible impact on warfarin anticoagulation response with their healthcare provider.

\subsection{Alcohol consumption}

Alcohol intake is another important factor in patients receiving warfarin, as this may increase or decrease the anticoagulant effect. Acute alcohol intake (e.g. ingestion of a few alcoholic drinks at a single sitting) may increase anticoagulation, via decreased hepatic metabolism of warfarin (69) or displacement of the drug from albumin with subsequent increase in unbound drug (70). Conversely, chronic consumption of alcohol may decrease the anticoagulant effect by activating cytochrome P450, thereby increasing the metabolism of warfarin (69). However, in an earlier literature review, Wells et al. concluded that alcohol potentiated warfarin anticoagulation only if the patient had concomitant liver disease. (71) A

Dutch study found that although habitual alcohol consumption or heavy drinking ( $\geq 6$ drinks/day) did not affect anticoagulation control, a recent decrease in alcohol intake increased the risk of having an INR value $\geq 6.0$ and thus increasing the risk of bleeding in the patient. (72) A case report of a patient on warfarin with a low-dose beer consumption was found to be the cause of elevated INR. The authors recommended close monitoring of INR when alcohol is taken in combination with warfarin and other concomitant medication. (73) In 
the absence of consistent data, it is clear that patients should either avoid alcohol or at least avoid erratic consumption of alcohol while receiving warfarin with close INR monitoring.

\subsection{Vitamin K supplementation}

Clinical experience indicates that only $50 \%$ to $60 \%$ of INRs measured are within target range in patients with monthly monitoring of treatment. (74) Low vitamin $\mathrm{K}$ levels cause a patient's warfarin dose requirement to vary with even minor changes in vitamin $\mathrm{K}$ intake.

Several recent studies have shown that daily oral supplementation with vitamin $\mathrm{K}$ could improve stability of anticoagulation control in patients who are more susceptible to dietary changes, because of their poor and erratic dietary vitamin $\mathrm{K}$ intake, such as the elderly. (21, 75-77) A small study in 2005 demonstrated that vitamin $\mathrm{K}$ supplementation improved anticoagulation control, possibly due to the more steady activation of vitamin $\mathrm{K}$-dependent clotting factors. (78) At the same time, our group demonstrated that patients with variably low dietary intake of vitamin $\mathrm{K}$ were more likely to have unstable control of anticoagulation compared to their matched stable counterparts. (79) Kim and colleagues in 2010 confirmed that patients with low vitamin $\mathrm{K}$ intake are more sensitive to minor changes in vitamin $\mathrm{K}$ intake and thus more likely to have unstable anticoagulation control. (80) Another prospective study proposed that a vitamin K-guided management strategy is clinically feasible for the maintenance of oral anticoagulation intensity. (81)

Schurgers and colleagues investigated the safe initiation of vitamin K supplementation on anticoagulation response in healthy subjects. They studied the dose-response relationship of vitamin $\mathrm{K}$ supplementation on anticoagulation control and concluded that the administration of $100 \mu \mathrm{g}$ of vitamin K daily did not significantly influence INR value. (82) Despite a study showing that $25 \mu \mathrm{g}$ significantly reduced the INR in patients with low vitamin $\mathrm{K}$ status (83), it was later recommended that supplementation with a $100 \mu \mathrm{g}$ vitamin $\mathrm{K}$ daily dose is preferable to negate any influence of variability in dietary vitamin $\mathrm{K}$ intake. (84) 
In 2007, three separate studies on the effect of vitamin $\mathrm{K}$ supplementation on anticoagulation stability reported similar findings. In a double-blinded placebo controlled study, seventy patients with unstable control of anticoagulation were randomised to receive either $150 \mu \mathrm{g}$ oral vitamin $\mathrm{K}$, or placebo daily for 6 months. The study confirmed that vitamin $\mathrm{K}$ supplementation results in significant improvement in anticoagulation stability attributed to a reduction in inter-day variability in dietary vitamin K intake. (76) A second open label crossover study of 9 patients with unstable anticoagulation control showed a reduction in INR variability after $500 \mu \mathrm{g}$ of oral vitamin $\mathrm{K}$ supplementation daily. (75) Rombouts and colleagues also demonstrated the positive effect on anticoagulation control of $100 \mu \mathrm{g}$ vitamin $\mathrm{K}$ supplementation once daily for 24 weeks in an unselected group of 200 patients on chronic therapy with phenprocoumon. (77)

A recent meta-analysis reported no beneficial effect of low-dose vitamin $K$ supplementation on the reduction of clinically relevant adverse events in patients taking VKAs. (85) However, the meta-analysis lacked sufficient data to show that daily vitamin $\mathrm{K}$ supplementation has an impact on the incidence of adverse events in anticoagulated patients. Based upon the overwhelming body of evidence that daily vitamin $\mathrm{K}$ supplementation improves anticoagulation stability the American College of Chest Physicians (ACCP) guidelines recommend the use of vitamin $\mathrm{K}$ in patients with chronically unstable anticoagulation. (86)

\subsection{Potential interaction between dietary vitamin $\mathrm{K}$ and direct oral anticoagulants}

In recent years, several direct oral anticoagulants (DOACs), which selectively inhibit a single clotting factor [factor Xa or factor Ila (thrombin)] have been developed with the aim of providing a more predictable pharmacokinetics and pharmacodynamics, thus obviating the need for patient monitoring. The factor Ila inhibitor, dabigatran, and factor Xa inhibitors, rivaroxaban, apixaban and edoxaban, have been provided license for the treatment of 
thrombosis as well as prevention of stroke after having demonstrated non-inferiority to warfarin in their clinical effectiveness for stroke prophylaxis in patients with atrial fibrillation. (87-90) It is generally accepted that, unlike coumarins, DOACs do not interact with dietary vitamin $\mathrm{K}$. This is because of the perception that the mode of action of these agents, which exert their pharmacological activity by inhibition of a specific clotting protein, is different to that of coumarins which inhibit the recycling of vitamin $\mathrm{K}$, necessary for the gamma-carboxylation and thus activation of vitamin K-dependent clotting proteins.

However, since the functionalisation of both factor Xa and thrombin is inextricably linked to vitamin $\mathrm{K}$, there is the possibility that the pharmacological activity of agents that inhibit these proteins could be influenced by alterations in vitamin $\mathrm{K}$ availability. Indeed in an earlier study in rats we demonstrated that vitamin $\mathrm{K}$ deficiency significantly enhanced the anticoagulation activity of the direct thrombin inhibitor, ximelagatran. Briefly, the anticoagulant activity of ximelagatran (20 mmol/kg, twice daily for 8 days) was significantly greater in rats on vitamin $\mathrm{K}$ deficient diet (12.3-fold for prothrombin time, 5.1-fold for activated partial thromboplastin time, and 1.6-fold for ecarin clotting time) compared to those on normal diet. Factor II activity was reduced to $58 \%$ by ximelagatran in rats on normal diet. However, factor II activity was virtually abolished $(<1 \%)$ by the drug in rats on vitamin $\mathrm{K}$ deficient diet.(91) Whether dietary vitamin $\mathrm{K}$ influences anticoagulation response to DOACs in man remains to be investigated.

\section{Conclusions}

Long-term oral anticoagulation with warfarin and other vitamin $\mathrm{K}$ antagonists places major limitations on patients in terms of what they can eat and drink. In particular, patients need to maintain a consistent dietary intake of vitamin $\mathrm{K}$, as sudden or marked changes in the intake of this vitamin (which can often be unintentional, e.g. initiation or withdrawal of dietary 
supplementation) can have a dramatic effect on anticoagulation control that can increase the risk of either thromboembolism due to under-coagulation or bleeding due to overanticoagulation. To minimise such risks to the patient it is therefore necessary to carry out additional INR monitoring and dose adjustment with the associated increase in the cost of anticoagulation therapy and the reduction in patient quality of life. Appropriate education of patients regarding the effects of diet and dietary supplementation on anticoagulation, emphasising the potential dangers of any sudden or marked changes in these factors, is therefore an important aspect of anticoagulation care. However, while improved patient education may help to reduce the risk of suboptimal anticoagulation control related to dietary changes in patients receiving long-term thromboprophylaxis with warfarin, clearly this will remain a difficult problem for many patients and their healthcare providers. Daily supplementation with oral vitamin $\mathrm{K}$ would be a good option in the attempt to improve anticoagulation control in patients with unstable anticoagulation suspected of having poor diets.

\section{Expert commentary}

There is a clear absence of consistency in the dietary intake among patients that receive warfarin or other vitamin $\mathrm{K}$ antagonists. Changing the dietary preferences or adding certain sources in patients' diet is not an effective and practical way of maintaining a stable anticoagulation control. Nevertheless, numerous studies including one from our group have shown that daily low dose oral vitamin $\mathrm{K}$ supplementation (100 to $200 \mathrm{mg}$ ) can improve anticoagulation outcomes and is simple to implement, because it does not interfere with individual dietary preference.

As part of the clinical management of patients on warfarin therapy, there should be a greater awareness among healthcare providers of the impact of malnutrition (in terms of dietary 
vitamin $\mathrm{K}$ intake), and the various foods and beverages that contain varying amounts of vitamin $\mathrm{K}$ on anticoagulation control.

There is experimental evidence in animals to suggest that ximelagatran interacts with dietary vitamin K. Further studies are needed to ascertain the presence of a pharmacodynamics interaction between dietary vitamin $\mathrm{K}$ and DOACs in man.

\section{Five-year view}

There is a compelling body of evidence on the impact of variable and poor dietary vitamin $\mathrm{K}$ on anticoagulation stability and the risk of bleeding in patients on warfarin therapy. Daily supplementation with low doses of oral vitamin $\mathrm{K}$ which leads to stabilisation of vitamin $\mathrm{K}$ stores in the liver have been shown to improve anticoagulation control in previously unstable patients. We along with a number of other anticoagulation services have adopted this approach. However, it is important that the benefits of vitamin $\mathrm{K}$ supplementation in patients on long-term therapy in the attempt to improving the safety of warfarin therapy are recognised on a wider scale. We are currently investigating the potential impact of dietary vitamin $\mathrm{K}$ on anticoagulation response to DOACs in man. The results of these studies are expected to become available soon. Should the results of these studies demonstrate the existence of an interaction between DOACs and dietary vitamin $\mathrm{K}$ then for patient safety reasons the introduction of some form of monitoring may become necessary.

\section{Key issues}

- Variable dietary vitamin $\mathrm{K}$ intake affects anticoagulation response to warfarin. 
- Warfarin interacts with a variety of foods, herbs and dietary supplements, which necessitates the need for better patient education about the effect of diet on anticoagulation control.

- Daily supplementation with low oral dose vitamin $\mathrm{K}$ increases stability of anticoagulation. Vitamin $\mathrm{K}$ supplementation has been embedded into guidelines for the management of anticoagulation with vitamin $\mathrm{K}$ antagonists.

Financial and competing interests disclosure: The authors report no conflicts of interest. 
Table 1. Phylloquinone (vitamin $\mathrm{K}_{1}$ ) content of foods (92)

\begin{tabular}{llll}
\hline Food item & $\begin{array}{l}\text { Phylloquinone } \\
\text { content }(\boldsymbol{\mu g} / \mathbf{1 0 0})\end{array}$ & Food item & $\begin{array}{l}\text { Phylloquinone } \\
\text { content }(\boldsymbol{\mu g} / \mathbf{1 0 0})\end{array}$ \\
\hline Vegetables & & Protein sources & \\
Collard greens & 440 & Dry soybeans & 47 \\
Spinach & 380 & Dry lentils & 22 \\
Salad greens & 315 & Liver & 5 \\
Broccoli & 180 & Eggs & 2 \\
Brussels sprouts & 177 & Fresh meats & $<1$ \\
Cabbage & 145 & Fresh fish & $<1$ \\
Bibb lettuce & 122 & Whole milk & $<1$ \\
Asparagus & 60 & Tuna in oil & 24 \\
Okra & 40 & & \\
Iceberg lettuce & 35 & Prepared foods & \\
Green beans & 33 & Salad dressings & 100 \\
Green peas & 24 & Coleslaw & 80 \\
Cucumber & 20 & Mayonnaise & 41 \\
Cauliflower & 20 & Beef chow mein & 31 \\
Carrots & 10 & Muffins & 25 \\
Tomatoes & 6 & Doughnuts & 10 \\
Potatoes & 1 & Apple pie & 11 \\
Fats and oils & & Potato chips & 15 \\
Soybean oil & 193 & French fries & 5 \\
Canola oil & 127 & Macaroni cheese & 5 \\
Cottonseed oil & 60 & Lasagne & 5 \\
Olive oil & 55 & Pizza & 4 \\
Corn oil & 3 & Hamburger/bun & 4 \\
Margarinea & & Bot dog/bun & 3 \\
Butter & & Baked beans & 3 \\
\hline Phitload & 3 \\
\hline
\end{tabular}

a Phylloquinone content may vary widely according to the source of oil used. 
Table 2. Adequate Intake (Al) of vitamin K (15)

\begin{tabular}{ccc}
\hline Life Stage & Age & Vitamin $\mathbf{K}(\boldsymbol{\mu g} / \mathbf{d a y})$ \\
\hline \multirow{2}{*}{ Infants } & $0-6$ months & 2.0 \\
& $7-12$ & 2.5 \\
& months & 30 \\
& 1-3 years & 55 \\
Children & 4-8 years & 60 \\
Adolescent & 9-13 years & 75 \\
S & 14-18 years & 120 (males) \\
Adults & $>19$ years & 90 (females) \\
\hline
\end{tabular}


Table 3. The K-Card (vitamin $\mathrm{K}$ intake assessment card) (from Couris et al. 2000)

\begin{tabular}{|c|c|c|c|c|c|c|c|c|c|}
\hline Food & One Serving & Phyloquinone incti & $\operatorname{sun}$ & Non & Fove & Wed & Thur & For & Sat \\
\hline \multicolumn{10}{|l|}{ Mixed dishesimeals } \\
\hline beet ehow mein (CNinese) & $1 \cos [5 \sec ]$ & 78 & & & & & & & \\
\hline macaroni and cheese & $1 \operatorname{cop}(8 \mathrm{es})$ & 10 & & & & & & & \\
\hline pizza & 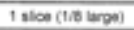 & 6 & & & & & & & \\
\hline lasagrespaghetti with mast surce & $1 \cos (5 \operatorname{\theta t})$ & 15 & & & & & & & \\
\hline tacostostadas (tast fosd) & 1 tases & $2 \mathrm{ag}$ & & & & & & & \\
\hline tuna cassercie & $\operatorname{tap}(5 \operatorname{sen})$ & ss & & & & & & & \\
\hline \multicolumn{10}{|l|}{ Desserts } \\
\hline cabobrownies & $1\left(z^{2}\right.$ square $)$ & 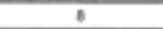 & & & & & & & \\
\hline coskies & Imostam & 3 & & & & & & & \\
\hline danishidoughnual & 1 modum & 10 & & & & & & & \\
\hline mumn & 1 modium & 14 & & & & & & & \\
\hline pie & 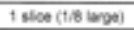 & 10 & & & & & & & \\
\hline \multicolumn{10}{|l|}{ Snacks } \\
\hline trocken & 6 crackins & 4 & & & & & & & \\
\hline popeom (poppesd in on & 2 oust $(2$ ans & 4 & & & & & & & \\
\hline prato enips & $1 \cos (\log x)$ & 4 & & & & & & & \\
\hline \multicolumn{10}{|l|}{ Fats/oiltudressings } \\
\hline canclassoybean of & I l thap & 27 & & & & & & & \\
\hline cthet oil & It thap & 4 & & & & & & & \\
\hline salad dreasing & 10 the & $\bar{T}$ & & & & & & & \\
\hline mayonasion & 1 thap & 6 & & & & & & & \\
\hline margarine & 9 thap & 5 & & & & & & & \\
\hline \multicolumn{10}{|l|}{ Supploments } \\
\hline perducts containing vitamin $\mathrm{K}$ & 65 micopians & 65 & & & & & & & \\
\hline High doose vitamin C & $1000 \mathrm{mg}$ & - & & & & & & & \\
\hline high dose vitamin $E$ & $1200 \mathrm{~N}$ & - & & & & & & & \\
\hline
\end{tabular}

Vitamin K Intake Assessment Card

$$
\text { (K-Card }{ }^{\circ} \text { ) }
$$

PJune 1997

R. Rebecca Couris \& Johanna T. Dwyer

Tufts University School of Nutrition Science and Policy

$\begin{array}{lr}\text { Name } & \text { Date } \\ \text { ID Number } & \text { Week }\end{array}$


K-Card (Check which foads you eat at each meat everyday. If you ear more ar less than one serving indicale how much.)

\begin{tabular}{|c|c|c|c|c|c|c|c|c|c|}
\hline Food & One Serving & Phylloquinone (mcg) & Sun & Man & Tue & Wod & Thur & Fin & Sat \\
\hline \multicolumn{10}{|l|}{ Meat'poultryfish } \\
\hline chicken (tried) & $3 \omega x$ & 4 & & & & & & & \\
\hline chicken nupgets & 6 nuppets & 2 & & & & & & & \\
\hline Fah sandalch (tast food) & 402 & 26 & & & & & & & \\
\hline fish sticks & 3 stioks & 6 & & & & & & & \\
\hline tona in ol (my form) & 3 ase & 20 & & & & & & & \\
\hline \multicolumn{10}{|l|}{ Vegetables } \\
\hline asparagus & $1 / 2$ cup & 72 & & & & & & & \\
\hline avecudo & 128 smat (6-8 stices) & 4 & & & & & & & \\
\hline bean pod & 122 and & 9 & & & & & & & \\
\hline broccoll & $1 / 2$ cus & 8 & & & & & & & \\
\hline Brussel sprout & $1 / 2$ cue & 225 & & & & & & & \\
\hline eabbouge & 12 sup & 73 & & & & & & & \\
\hline cauliflower & $1 / 2040$ & 12 & & & & & & & \\
\hline chick peasigarbanzos (nummus) & $1 / 2$ <4e & 12 & & & & & & & \\
\hline coloslaw with dressing & 1/2 cup & 65 & & & & & & & \\
\hline eucumber with peet & 12 cus & 20 & & & & & & & \\
\hline endive & $12 \cos$ & 185 & & & & & & & \\
\hline green beans & $1 / 2$ ens & 14 & & & & & & & \\
\hline greens (collang) & $1 / 2040$ & 375 & & & & & & & \\
\hline greers (tumip/mustard) & 12 cup & 200 & & & & & & & \\
\hline kale & 12 cusp & 680 & & & & & & & \\
\hline lettuce & 1 cup & $\Leftrightarrow$ & & & & & & & \\
\hline mixed vegotables & 12 cup & 15 & & & & & & & \\
\hline okra & $1 / 2$ cup & 32 & & & & & & & \\
\hline pees & 12 cup & 19 & & & & & & & \\
\hline Dickle (diil) & 1 speat & 6 & & & & & & & \\
\hline potato (trench tries) & 1 oup & 5 & & & & & & & \\
\hline swoerkrims & 128 cus & 15 & & & & & & & \\
\hline scalions & $1 / 2$ cup & 100 & & & & & & & \\
\hline soyteanstofu & $1 / 2$ cup & 150 & & & & & & & \\
\hline spinach & $1 / 2$ cup & 324 & & & & & & & \\
\hline \multicolumn{10}{|l|}{ Beverages } \\
\hline v8 juice & $1 \cos (6 \cos )$ & is & & & & & & & \\
\hline green tea & 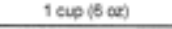 & - & & & & & & & \\
\hline
\end{tabular}


Table 4. Vitamin $\mathrm{K}$ content of various enteral feeds ready-to-drink according to the British National Formulary, $2017^{\wedge}$

\begin{tabular}{|c|c|c|}
\hline Product & Kcal & Vitamin K content $(\mu \mathrm{g})$ \\
\hline \multicolumn{3}{|c|}{ Per $100 \mathrm{~mL}$ serving } \\
\hline Fresubin $^{\circledR}$ original $^{a}$ & 100 & 6.7 \\
\hline Fresubin $®$ original fibre a & 100 & 6.7 \\
\hline Fresubin ${ }^{\circledR} 1000$ complete $^{a}$ & 418 & 10 \\
\hline Fresubin ${ }^{\circledR} 1200$ complete ${ }^{a}$ & 500 & 10 \\
\hline Fresubin ${ }^{\circledR} 1500$ complete $^{a}$ & 420 & 6.7 \\
\hline Fresubin ${ }^{\circledR} 1800$ complete ${ }^{a}$ & 500 & 10 \\
\hline \multicolumn{3}{|l|}{ Fresubin $® 2250$ complete ${ }^{a}$} \\
\hline $\begin{array}{l}\text { Fresubin } ® \text { energy a } \\
\text { Fresubin } \AA \text { energy fibre }{ }^{a} \\
\text { Fresubin } ® \text { HP energy a }\end{array}$ & 630 & 6.67 \\
\hline Ensure TwoCal b & 200 & 8.5 \\
\hline $\begin{array}{l}\text { Nutrison }{ }^{\circledR} \mathrm{c} \\
\text { Nutrison }{ }^{\circledR} \text { MCT } \mathrm{c}\end{array}$ & 100 & 5.3 \\
\hline Nutrison $\circledast$ Multi Fibre ${ }^{c}$ & 103 & 5.3 \\
\hline Nutrison $®$ Energy ${ }^{c}$ & 150 & 8 \\
\hline Nutrison $\circledast$ Energy Multi Fibre ${ }^{c}$ & 153 & 8 \\
\hline Nutrison $\circledast$ Protein Plus ${ }^{c}$ & 125 & 6.6 \\
\hline Nutrison ${ }^{\circledR}$ Protein Plus Multi Fibre ${ }^{c}$ & 128 & 6.6 \\
\hline Nutrison ${ }^{\circledR} 800$ Complete Multi Fibre ${ }^{c}$ & 83 & 8 \\
\hline Nutrison $\circledast 1000$ Complete Multi Fibre ${ }^{c}$ & 104 & 8 \\
\hline Resource Energy d & 151 & 14 \\
\hline Peptamen $\circledast \mathrm{HN}^{\mathrm{d}}$ & 133 & 9 \\
\hline Vital $1.5 \mathrm{kcal}{ }^{b}$ & 150 & 7 \\
\hline Novasource $®$ GI Control d & 106 & 6 \\
\hline Novasource $₫ \mathrm{GI}$ Control ${ }^{\mathrm{d}}$ & 155 & 11 \\
\hline \multicolumn{3}{|c|}{ Per $8 \mathrm{fl}$ oz serving * } \\
\hline Jevity ${ }^{\circledR}$ Cal ${ }^{b}$ & 250 & 15 \\
\hline Jevity 1.2 Cal (formerly Jevity Plus) ${ }^{b}$ & 285 & 20 \\
\hline Jevity® $1.5 \mathrm{Cal}^{\mathrm{b}}$ & 355 & 19 \\
\hline Osmolite $₫ 1 \mathrm{Cal}{ }^{\mathrm{b}}$ & 250 & 15 \\
\hline Osmolite ${ }^{\circledR} 1.2 \mathrm{Cal}^{\mathrm{b}}$ & 285 & 20 \\
\hline Osmolite $® 1.5 \mathrm{Cal}^{\mathrm{b}}$ & 355 & 19 \\
\hline
\end{tabular}


Ensure® b

Ensure ${ }^{\circledR}$ High Protein ${ }^{b}$

Ensure ${ }^{\circ}$ Plus ${ }^{b}$

Ensure ${ }^{\circledR}$ Plus HN b

Ensure ${ }^{\circledR}$ Enlive ${ }^{\circledR}$ Advanced Nutrition

Shake ${ }^{b}$

Two cal $\circledast$ b

Perative ${ }^{\circledR} \mathrm{b}$
220

160

350

250

350

475

308
20

20

20

20

20

20

17

$\wedge$ Information retrieved from https://www.evidence.nhs.uk/formulary/bnf/current/; accessed 14 February, 2017)

a Information retrieved from Fresenius Kabi (http://www.fresenius-kabi.co.uk/4727.htm; accessed 14 February, 2017)

${ }^{\mathrm{b}}$ Information retrieved from Abbott (https://abbottnutrition.com/; accessed 14 February, 2017)

c Information retrieved from Nutricia Clinical (http://www.nutricia.co.uk/; accessed 15 February, 2017)

d Information retrieved from Nestlé HealthCare Nutrition

(https://www.nestlehealthscience.co.uk;accessed 15 February, 2017)

${ }^{*} 8 \mathrm{fl} \mathrm{oz}(\mathrm{US})=237 \mathrm{ml}$ 


\section{References}

1. GBD 2013 Mortality and Causes of Death Collaborators. Global, regional, and national age-sex specific all-cause and cause-specific mortality for 240 causes of death, 1990-2013: a systematic analysis for the Global Burden of Disease Study 2013. Lancet. 2015;385:117-71.

2. Singer D. Anticoagulation to prevent stroke in atrial fibrillation and its implications for managed care. Am J Cardiol. 1998;Mar 12;81(5A):35C-40C.

3. Wolf $P$, Abbott R, Kannel W. Atrial fibrillation as an independent risk factor for stroke: the Framingham Study. Stroke. 1991;22:983-88.

4. Kannel W, Benjamin E. Final Draft Status of the Epidemiology of Atrial Fibrillation. The Medical clinics of North America. 2008;92(1):17-ix.

5. Mozaffarian D, Benjamin E, Go A, Arnett D, Blaha M, Cushman M, et al. Heart disease and stroke statistics--2015 update: a report from the American Heart Association. Circulation. 2015;131(4):e29-322.

6. Heit J, Spencer F, White R. The epidemiology of venous thromboembolism. J Thromb Thrombolysis. 2016;41:3-14.

7. Van Walraven C, Hart R, Singer D, Laupacis A, Connolly S, Petersen P, et al. Oral anticoagulants vs aspirin in nonvalvular atrial fibrillation. An individual patient meta-analysis. JAMA 2002;288:2441-8.

8. Hart R, Pearce L, Aguilar M. Meta-analysis: antithrombotic therapy to prevent stroke in patients who have nonvalvular atrial fibrillation. Ann Intern Med. 2007; Jun 19; 146(12):857-67.

9. You J, Singer D, Howard P, Lane D, Eckman M, Fang M, et al. Antithrombotic Therapy for Atrial Fibrillation: Antithrombotic Therapy and Prevention of Thrombosis, 9th ed: American College of Chest Physicians Evidence-Based Clinical Practice Guidelines. Chest. 2012;141(2 Suppl):e531S-e75S.

10. Tie J, Stafford D. Structural and functional insights into enzymes of the vitamin K cycle. J Thromb Haemost. 2016;Feb;14(2):236-47.

*11. Lubetsky A, Dekel-Stern E, Chetrit A, Lubin F, Halkin H. Vitamin K intake and sensitivity to warfarin in patients consuming regular diets. Thromb Haemost.

1999;Mar;81(3):396-9. *(Influence of vitamin K on warfarin dose)

12. Franco V, Polanczyk C, Clausell N, Rohde L. Role of dietary vitamin K intake in chronic oral anticoagulation: prospective evidence from observational and randomized protocols. Am J Med. 2004;May 15;116(10):651-6.

13. Booth S. Dietary vitamin K guidance: an effective strategy for stable control of oral anticoagulation? Nutr Rev. 2010;Mar;68(3):178-81.

14. Sokoll L, Booth S, O'Brien M, Davidson K, Tsaioun K, Sadowski J. Changes in serum osteocalcin, plasma phylloquinone, and urinary gamma-carboxyglutamic acid in response to altered intakes of dietary phylloquinone in human subjects. Am J Clin Nutr. 1997;Mar;65(3):779-84.

15. Food and Nutrition Board, Institute of Medicine. Dietary reference intakes for vitamin $\mathrm{A}$, vitamin $\mathrm{K}$, arsenic, boron, chromium, copper, iodine, iron, manganese, molybdenum, nickel, silicon, vanadium, and zinc. National Academy Press, editor. Washington, DC;2001.

16. Thane C, Paul A, Bates CJ, Bolton-Smith C, Prentice A, Shearer MJ. Intake and sources of phylloquinone (vitamin $\mathrm{K} 1$ ): variation with socio-demographic and 
lifestyle factors in a national sample of British elderly people. $\mathrm{Br} \mathrm{J}$ Nutr. 2002;87(6):605-13.

17. Booth S, Sokoll L, O'Brien M, Tucker K, Dawson-Hughes B, Sadowski J. Assessment of dietary phylloquinone intake and vitamin $\mathrm{K}$ status in postmenopausal women. Eur J Clin Nutr. 1995;Nov;49(11):832-41.

18. Chow W, Chow T, Tse T, Tai Y, Lee' W. Anticoagulation instability with lifethreatening complication after dietary modification. Postgrad Med J. 1990;66(855857).

19. Walker F. Myocardial infarction after diet-induced warfarin resistance. Arch Intern Med 1984;Oct;144(10):2089-90.

20. Pedersen $\mathrm{F}$, Hamberg $\mathrm{O}$, Hess K, Ovesen $\mathrm{L}$. The effect of dietary vitamin $\mathrm{K}$ on warfarin-induced anticoagulation. J Intern Med. 1991;Jun;229(6):517-20.

${ }^{* *} 21$. Khan T, Wynne H, Wood P, Torrance A, Hankey C, Avery P, et al. Dietary vitamin $\mathrm{K}$ influences intra-individual variability in anticoagulant response to warfarin. Br J Haematol. 2004;Feb;124(3):348-54. (**The influence of dietary vitamin K on anticoagulation stability)

*22. Couris R, Tataronis G, Booth S, Dallal G, Blumberg J, Dwyer J. Development of a self-assessment instrument to determine daily intake and variability of dietary vitamin K. J Am Coll Nutr. 2000;Nov-Dec;19(6):801-7.(K-card for self-assessment of dietary vitamin $\mathrm{K}$ ).

23. Dickerson R. Warfarin resistance and enteral tube feeding: a vitamin Kindependent interaction. Nutrition. 2008;Oct;24(10):1048-52.

24. Penrod L, Allen J, Cabacungan L. Warfarin resistance and enteral feedings: 2 case reports and a supporting in vitro study. Arch Phys Med Rehabil. 2001;Sep;82(9):1270-3.

25. Shearer M. Vitamin K in parenteral nutrition. Gastroenterology. 2009;Nov;137(5 Suppl):S105-18.

26. Klang M, Graham D, McLymont V. Warfarin bioavailability with feeding tubes and enteral formula. JPEN J Parenter Enteral Nutr. 2010;May-Jun;34(3):300-4.

27. Bonduel M. Oral anticoagulation therapy in children. Thrombosis Research. 2006;118:85-94.

28. Clarke P, Mitchell S, Shearer M. Total and Differential Phylloquinone (Vitamin K1) Intakes of Preterm Infants from All Sources during the Neonatal Period. Nutrients. 2015;Oct; 7(10):8308-20.

29. Kurnik D, Lubetsky A, Loebstein R, Almog S, Halkin H. Multivitamin supplements may affect warfarin anticoagulation in susceptible patients. Ann Pharmacother. 2003;Nov;37(11):1603-6.

30. Booth S, Golly I, Sacheck J, Roubenoff R, Dallal G, Hamada K, et al. Effect of vitamin $\mathrm{E}$ supplementation on vitamin $\mathrm{K}$ status in adults with normal coagulation status. Am J Clin Nutr. 2004;Jul;80(1):143-8.

31. Heck A, DeWitt $B$, Lukes A. Potential interactions between alternative therapies and warfarin. Am J Health Syst Pharm. 2000;Jul 1;57(13):1221-7.

32. Sontag T, Parker R. Cytochrome P450 omega-hydroxylase pathway of tocopherol catabolism. Novel mechanism of regulation of vitamin E status. J Biol Chem. 2002; Jul 12;277(28):25290-6.

33. Kim J, White R. Effect of vitamin $E$ on the anticoagulant response to warfarin. Am J Cardiol. 1996;Mar 1;77(7):545-6. 
34. Stenton S, Bungard T, Ackman M. Interactions between Warfarin and Herbal Products, Minerals, and Vitamins: A Pharmacist's Guide. Can J Hosp Pharm. 2001;54(3):186-92.

35. Harris J. Interaction of dietary factors with oral anticoagulants: review and applications. J Am Diet Assoc. 1995;May;95(5):580-4.

36. Deckert F. Ascorbic acid and warfarin. JAMA. 1973;223:440.

37. Khoshvaghti A, Nazifi S, Akbarpour B, Razavi S. The effects of vitamin C on vitamin K-related clotting factors. Comparative Clinical Pathology. 2011;20(5):513-7. 38. Weintraub M, Griner P. Warfarin and ascorbic acid: lack of evidence for a drug interaction. Toxicol Appl Pharmacol. 1974;28:53-6.

39. Wynne H, Khan T, Avery P, Wood P, Ward A, Kamali F. Dietary related plasma vitamin $\mathrm{C}$ concentration has no effect on anticoagulation response to warfarin. Thromb Res. 2006;118(4):501-4.

40. Pepping J. Coenzyme Q10. Am J Health Syst Pharm. 1999;Mar 15;56(6):519-

21.

41. Spigset $O$. Reduced effect of warfarin caused by ubidecarenone. Lancet. 1994;Nov 12;344(8933):1372-3.

42. Morton R. Ubiquinones, plastoquinones and vitamins K. Biol Rev Camb Philos Soc. 1971;Feb;46(1):47-96.

43. Combs A, Porter T, Folkers K. Anticoagulant activity of naphthoquinone analog of vitamin $\mathrm{K}$ and an inhibitor of Coenzyme Q10 -enzyme systems. Res Commun Chem Pathol Pharmacol. 1976;13:109-14.

44. Landbo C, Almdal T. Interaction between warfarin and coenzyme Q10. Ugeskr Laeger. 1998;160:3226-7.

45. Spigset $O$. Reduced effect of warfarin caused by ubidecarenone. Lancet. 1994;344:1372-3.

46. Engelsen J, Nielsen J, Hansen K. Effect of coenzyme Q10 and ginkgo biloba on warfarin dosage in patients on long-term warfarin treatment. A randomized, double-blind, placebo-controlled cross-over trial (in Danish). Ugeskr Laeger 2003;165:1868-71.

47. Buckley M, Goff A, Knapp W. Fish oil interaction with warfarin. Ann Pharmacother. 2004;Jan;38(1):50-2.

48. Bender N, Kraynak M, Chiquette E, Linn W, Clark G, Bussey H. Effects of Marine Fish Oils on the Anticoagulation Status of Patients Receiving Chronic Warfarin Therapy. J Thromb Thrombolysis. 1998;Jul;5(3):257-61.

49. Cambria-Kiely J. Effect of soy milk on warfarin efficacy. Ann Pharmacother. 2002;Dec;36(12):1893-6.

50. Martinez E, Domingo P, Roca-Cusachs A. Potentiation of acenocoumarol action by L-carnitine. J Intern Med. 1993;Jan;233(1):94.

51. Bachmann $\mathrm{H}$, Hoffmann A. Interaction of food supplement L-carnitine with oral anticoagulant acenocoumarol. Swiss Med Wkly. 2004;Jun 26;134(25-26):385.

52. Izzo A, Ernst E. Interactions between herbal medicines and prescribed drugs: an updated systematic review. Drugs. 2009;69(13):1777-98.

53. Hu Z, Yang X, Ho P, Chan S, Heng P, Chan E, et al. Herb-Drug Interactions: A Literature Review. Drugs. 2005;65(9):1239-82.

54. Ge B, Zhang Z, Zuo Z. Updates on the Clinical Evidenced Herb-Warfarin Interactions: eCAM. Evid Based Complement Alternat Med. 2014;2014:957362. 
55. Henderson L, Yue Q, Bergquist C, Gerden B, Arlett P. St John's wort (Hypericum perforatum): drug interactions and clinical outcomes. Br J Clin Pharmacol. 2002;Oct;54(4):349-56.

56. Haller C. Clinical approach to adverse events and interactions related to herbal and dietary supplements. Clin Toxicol (Phila). 2006;44(5):605-10.

57. Izzat M, Yim A, El-Zufari M. A taste of Chinese medicine. Ann Thorac Surg. 1998;66:941-2.

58. Hamann G, Campbell J, George C. Warfarin-Cranberry Juice Interaction Ann Pharmacother. 2011;45(3):e17.

59. Paeng $C$, Sprague M, Jackevicius $C$. Interaction between warfarin and cranberry juice. Clin Ther. 2007;Aug;29(8):1730-5.

60. Mergenhagen K, Sherman O. Elevated International Normalized Ratio after concurrent ingestion of cranberry sauce and warfarin. Am J Health Syst Pharm. 2008;Nov;65(22):2113-6.

61. Suvarna R, Pirmohamed M, Henderson L. Possible interaction between warfarin and cranberry juice. BMJ. 2003;327:1454.

62. Beckmann-Knopp S, Rietbrock S, Weyhenmeyer R, Böcker R, Beckurts K, Lang W, et al. Inhibitory effects of silibinin on cytochrome P-450 enzymes in human liver microsomes. Pharmacol Toxicol. 2000;Jun;86(6):250-6.

63. Bartle W. Grapefruit juice might still be factor in warfarin response. Am J Health Syst Pharm 1999;56(7):676.

64. Sullivan D, Ford M, Boyden T. Grapefruit juice and the response to warfarin. Am J Health Syst Pharm. 1998;Aug 1;55(15):1581-3.

65. Veronese M, Gillen L, Burke J, Dorval E, Hauck W, Pequignot E, et al. Exposure-dependent inhibition of intestinal and hepatic CYP3A4 in vivo by grapefruit juice. Journal of Clinical Pharmacology. 2003;43(8):831-9.

66. Guo L, Yamazoe Y. Inhibition of cytochrome P450 by furanocoumarins in grapefruit juice and herbal medicines. Acta Pharmacologica Sinica. 2004;25(2):12936.

67. Booth S, Sadowski J, Weihrauch J, Ferland G. Vitamin K1 (phylloquinone) content of foods: a provisional table. Journal of Food Composition and Analysis 1993;6(2):109-20.

68. Taylor J, Wilt V. Probable antagonism of warfarin by green tea. Annals of Pharmacotherapy. 1999;33(4):426-8.

69. Weathermon R, Crabb D. Alcohol and medication interactions. Alcohol Res Health. 1999;23(1):40-54.

70. Ha C, Petersen C, Park D, Harohalli K, Bhagavan N. Investigations of the effects of ethanol on warfarin binding to human serum albumin. J Biomed Sci 2000;Mar-Apr;7(2):114-21.

71. Wells $P$, Holbrook A, Crowther $N$, Hirsh J. Interactions of warfarin with drugs and food. Ann Intern Med. 1994;Nov 1;121(9):676-83.

72. Penning-van Beest F, Geleijnse J, van Meegen E, Vermeer C, Rosendaal F, Stricker B. Lifestyle and diet as risk factors for overanticoagulation. J Clin Epidemiol. 2002; Apr;55(4):411-7.

73. Havrda D, Mai T, Chonlahan J. Enhanced antithrombotic effect of warfarin associated with low-dose alcohol consumption. Pharmacotherapy. 2005; 25(2):303-7

74. Stroke Prevention in Atrial Fibrillation Investigators. Adjusted dose warfarin versus low intensity, fixed dose warfarin plus aspirin for high risk patients with atrial 
fibrillation: Stroke Prevention in Atrial Fibrillation III Randomised Clinical Trial. Lancet. 1996;348:633-8.

75. Ford S, Misita C, Shilliday B, Malone R, Moore C, Moll S. Prospective study of supplemental vitamin $\mathrm{K}$ therapy in patients on oral anticoagulants with unstable international normalized ratios. J Thromb Thrombolysis. 2007;Aug;24(1):23-7. ${ }^{* *} 76$. Sconce E, Avery P, Wynne H, Kamali F. Vitamin K supplementation can improve stability of anticoagulation for patients with unexplained variability in response to warfarin. Blood. 2007; Mar 15;109(6):2419-23. ( ${ }^{* *}$ first report of the effect of daily vitamin $\mathrm{K}$ supplementation on anticoagulation stability)

77. Rombouts E, Rosendaal F, Van der meer F. Daily vitamin K supplementation improves anticoagulant stability. Journal of Thrombosis and Haemostasis. 2007;5:2043-8.

78. Reese A, Farnett L, Lyons R, Patel B, Morgan L, Bussey H. Low-dose vitamin $\mathrm{K}$ to augment anticoagulation control. Pharmacotherapy. 2005;25(12):1746-51. **79. Sconce E, Khan T, Mason J, Noble F, Wynne H, Kamali F. Patients with unstable control have a poorer dietary intake of vitamin $\mathrm{K}$ compared to patients with stable control of anticoagulation. Thromb Haemost. 2005;May;93(5):872-5.

( ${ }^{* *}$ showing the effect of variable vitamin $\mathrm{K}$ intake on anticoagulation control)

80. Kim K, Choi W, Lee J, Lee H, Yang D, Chae S. Relationship between dietary vitamin $\mathrm{K}$ intake and the stability of anticoagulation effect in patients taking long-term warfarin. Thromb Haemost. 2010;Oct;104(4):755-9.

81. de Assis M, Rabelo E, Avila C, Polanczyk C, Rohde L. Improved Oral Anticoagulation After a Dietary Vitamin K-Guided Strategy. Circulation. 2009;120:1115-22.

82. Schurgers L, Shearer M, Hamulyak K, Stocklin E, Vermeer C. Effect of vitamin $\mathrm{K}$ intake on the stability of oral anticoagulant treatment: dose-response relationships in healthy subjects. Blood. 2004;104:2682-9.

83. Kurnik D, Loebstein R, Rabinovitz H, Austerweil N, Halkin H, Almog S. Overthe-counter vitamin $\mathrm{K} 1$-containing multivitamin supplements disrupt warfarin anticoagulation in vitamin K1-depleted patients. A prospective, controlled trial. Thromb Haemost. 2004;Nov;92(5):1018-24.

84. Oldenburg J. Vitamin K intake and stability of oral anticoagulant treatment. Thromb Haemost 2005;93:799-800.

85. Lam J, Schulman S, Witt D, Vandvik P, Qayyum F, Holbrook A.

Anticoagulation control with daily low-dose vitamin $\mathrm{k}$ to reduce clinically adverse outcomes and international normalized ratio variability: a systematic review and meta-analysis. Pharmacotherapy. 2013;Nov;33(11):1184-90.

*86. Ansell J, Hirsh J, Hylek E, Jacobson A, Crowther M, Palareti G, et al. Pharmacology and management of the vitamin $\mathrm{K}$ antagonists: American College of Chest Physicians Evidence-Based Clinical Practice Guidelines (8th Edition). Chest. 2008;Jun;133(6 Suppl):160S-98S.

87. Connolly SJ, Ezekowitz MD, Yusuf S, Eikelboom J, Oldgren J, Parekh A, et al. Dabigatran versus warfarin in patients with atrial fibrillation. New England Journal of Medicine. 2009;361(12):1139-51.

88. Patel MR, Mahaffey KW, Garg J, Pan G, Singer DE, Hacke W, et al. Rivaroxaban versus warfarin in nonvalvular atrial fibrillation. New England Journal of Medicine. 2011;365(10):883-91. 
89. Granger CB, Alexander JH, McMurray JJ, Lopes RD, Hylek EM, Hanna M, et al. Apixaban versus warfarin in patients with atrial fibrillation. New England Journal of Medicine. 2011;365(11):981-92.

90. Giugliano RP, Ruff CT, Braunwald E, Murphy SA, Wiviott SD, Halperin JL, et al. Edoxaban versus warfarin in patients with atrial fibrillation. The New England journal of medicine. 2013;369(22):2093-104.

${ }^{* *} 91$. Kamali F, Wood P, Ward A. Vitamin K deficiency amplifies anticoagulation response to ximelagatran: possible implications for direct thrombin inhibitors and their clinical safety. Ann Hematol. 2009;Feb;88(2):141-9.(**first study showing the existence of an interaction between dietary vitamin $\mathrm{K}$ and ximelagatran) 92. Booth S, Suttie J. Dietary intake and adequacy of Vitamin K. J Nutr. 1998;128:785-8. 